\title{
Earthquake Doublet Sequences: Evidence of Static Triggering in the Strong Convergent Zones of Taiwan
}

\author{
Cheng-Horng Lin ${ }^{1, *}$, Yih-Hsiung Yeh $^{1}$, Masataka Ando ${ }^{1}$, Kuang-Jung Chen ${ }^{2}$, \\ Tao-Ming Chang ${ }^{3}$, and Hsin-Chieh $\mathrm{Pu}^{4}$ \\ ${ }^{1}$ Institute of Earth Sciences, Academia Sinica, Taipei, Taiwan, ROC \\ ${ }^{2}$ Department of Earth Sciences, National Taiwan Normal University, Taipei, Taiwan, ROC \\ ${ }^{3}$ National Center for Research on Earthquake Engineering, Taipei, Taiwan, ROC \\ ${ }^{4}$ Institute of Geophysics, National Central University, Chung-Li, Taiwan, ROC
}

Received 17 December 2007, accepted 26 September 2008

\begin{abstract}
Three earthquake sequences, each with two main earthquakes of almost the same magnitudes $\left(\mathrm{M}_{\mathrm{L}}\right.$ from 5.9 to 7.0 with differences less than 0.1), have recently been observed in Taiwan. The two largest earthquakes in each sequence occurred with a short delay time between them, were strikingly similar in terms of magnitude, location and/or focal mechanism and are referred to as doublets. They were markedly distinct from typical single mainshock sequences. Our estimated static stress field generated by the first shock in the doublet shows that the second shock and most of their aftershocks were located within a region where static stress increased substantially. Thus, a possible explanation for earthquake doublet is that seismic energy for each shock had accumulated independently within adjacent crustal volumes, separated by an asperity, and that the second shock is triggered by the increased static stress after the first one. An important implication of doublet sequence is that works by emergency response teams after the first earthquake could be made more hazardous by the second.
\end{abstract}

Key words: Doublet earthquake, Static triggering, Aftershocks

Citation: Lin, C. H., Y. H. Yeh, M. Ando, K. J. Chen, T. M. Chang, and H. C. Pu, 2008: Earthquake doublet sequences: Evidence of static triggering in the strong convergent zones of Taiwan. Terr. Atmos. Ocean. Sci., 19, 589-594, doi: 10.3319/TAO.2008.19.6.589(PT)

\section{INTRODUCTION}

On 26 December 2006, an earthquake sequence with two identical major earthquakes $\left(\mathrm{M}_{\mathrm{L}}=7.0\right)$ occurred off the southwest coast of Taiwan, approximately $20 \sim 30 \mathrm{~km}$ west southwest of Hengchun, a small town at the southern tip of Taiwan (Fig. 1). Both the Japan Meteorological Agency and the Pacific Tsunami Warning Center immediately issued a tsunami warning for the South China Sea region, particularly the northern Luzon islands. Although there was ultimately no direct tsunami damage, the earthquake sequence did sever several submarine communication cables and disrupted Internet services in Asia. Also two residents in Hengchun were killed in a house that collapsed after the second major earthquake. In addition to this damage, one of the most salient points for the scientific community is that the two major earthquakes virtually had the same magnitude $\left(\mathrm{M}_{\mathrm{L}}=7.0\right)$

\footnotetext{
* Corresponding author

E-mail:lin@earth.sinica.edu.tw
}

and were only 8 minutes apart. It has historically been rare that two major earthquakes of similar magnitude with only a short time-span between them.

As rare as the Hengchun doublet was, it was not in fact unprecedented because two other instances were found in the Taiwan area. We have carefully examined all of 214 earthquakes $\left(\mathrm{M}_{\mathrm{L}}>5.5\right)$ listed on the Earthquake Catalogue from 1974 to 2006 and found another two earthquake sequences with two identical moderate or strong earthquakes whose magnitude differences are less than 0.1. They were the Suao doublet on 6 March 2005 and the South China Sea doublet on 8 Oct. 2006. The local magnitudes $\left(\mathrm{M}_{\mathrm{L}}\right)$ of the two largest earthquakes were 6.0 and 5.9 in the Suao sequence, and 6.1 and 6.1 in the South China Sea sequence. In addition to being close in magnitude, the two largest earthquakes in each earthquake sequence were in close proximity in both time and space. In short, these two as well as the Hengchun doublets share distinct characteristics and deserve further study. 


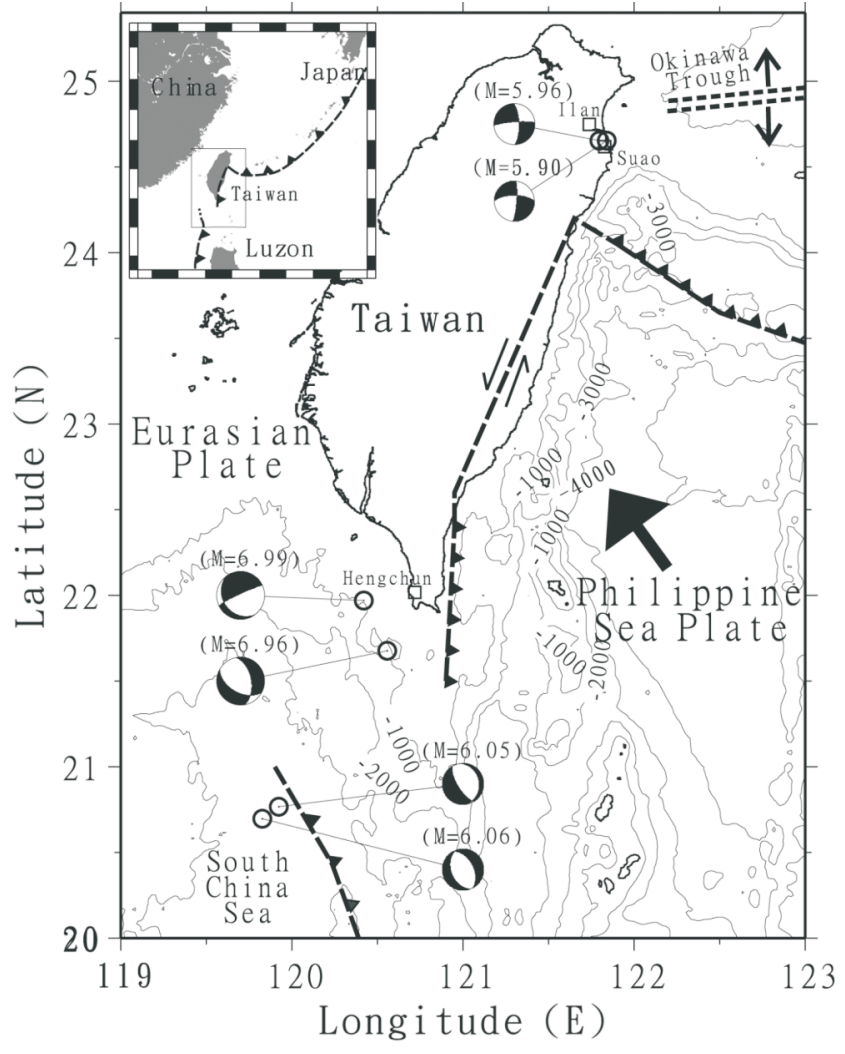

Fig. 1. Locations and focal mechanisms of the three sets of doublet-shocks in the Taiwan area. The general tectonics including the plate motion (large arrow), subduction (thick dashed lines with triangles), and suture zone (thick dashed line with double arrows) are shown in the map.

These three earthquake sequences stand in stark contrast to the typical earthquake sequence, where one mainshock is easily identified because of its significantly larger magnitude when compared with that of other earthquakes in the sequence. Under what circumstances a doublet instead of a single mainshock occurs becomes a difficult, yet interesting, problem. It must be noted that rescue work after the first shock could become very dangerous if the earthquakes that follow have seismic energy as great as (or even greater than) the first earthquake. Therefore, understanding the possible mechanisms that generate those doublet-shocks may help us eventually in reducing hazards for the rescue teams.

In this study, we first look at the temporal and spatial relations of the earthquakes in the three doublets using hypocentral determinations reported by the Central Weather Bureau in Taiwan. We then calculate the changes in static stress (Okada 1985) after the first shock of each doublet based on the focal mechanisms determined by the Broadband Array in Taiwan for Seismology (BATS) and the National Earthquake Information Center (NEIC). Finally, we summarize the general characteristics of doublets and discuss the possible mechanisms for their generation.

\section{DOUBLET EARTHQUAKES}

The earthquake data used in this study were recorded by two seismic networks in the Taiwan area, the Central Weather Bureau Seismic Networks (CWBSN), with 79 stations on Taiwan (Shin et al. 2000) and offshore islands, and BATS, with a total of 22 stations. We use location information from the CWB Earthquake Catalogue and the Central Moment Tensor (CMT) solutions from BATS (Kao and Jian 1999). The NEIC CMT solutions are used for earthquakes whose focal mechanisms are not determined by the BATS. We first present the origin times, locations and focal mechanisms for the three doublets.

\subsection{The Suao Earthquakes}

On 6 March 2005, the first of our three doublets took place near Suao harbor in the Ilan plain (Fig. 2a), located

(a)
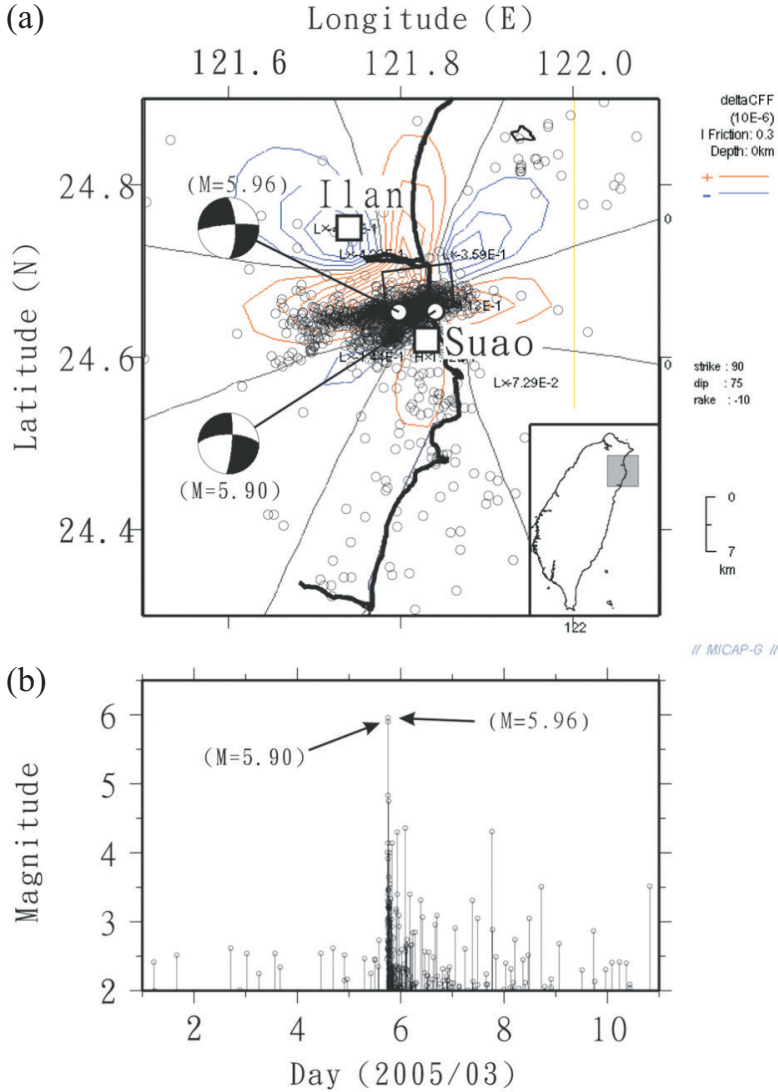

Fig. 2. (a) Seismicity and focal mechanisms of the two moderate earthquakes in the Suao earthquake sequence. The contours in this and in the following figures show the delta CFF on the surface generated by the dislocation along the inclined dip-slip fault (a rectangle) of the $1^{\text {st }}$ largest earthquake. The red contours are for stress increase and blue are stress decrease. The locations of Suao and Ilan towns are marked by squares. The insert map shows the location of the earthquake sequence marked in grey in the Taiwan area. (b) Time variations in the earthquake sequence. Arrows indicate the two largest earthquakes. 
near the western end of the Okinawa Trough. The seismicity in the Suao area is high (Fig. 3); it is associated with the complex tectonic effects of both the northward subduction of the Philippine Sea plate and the opening of the Okinawa Trough (Liu 1995). Based on CWBSN data, two moderate earthquakes, almost identical in magnitude $\left(\mathrm{M}_{\mathrm{L}}=5.9\right.$ and $6.0)$, occurred at $\left(121.84^{\circ} \mathrm{E}, 24.65^{\circ} \mathrm{N}, 6.4 \mathrm{~km}\right)$ and $\left(121.80^{\circ} \mathrm{E}, 24.65^{\circ} \mathrm{N}, 7.0 \mathrm{~km}\right)$. Their occurrence times were only 68 seconds apart (Fig. 2b). In addition to their physical proximity, the CMT solutions determined by the regional broadband seismic network (BATS) were almost the same (Fig. 2a). Based on the EW-elongated aftershock zone in the few days that followed the two moderate earthquakes, the EW-striking left-lateral fault plane was taken as the rupture plane. In short, the two earthquakes not only occurred within a short time-span but also exhibited remarkable similarities in terms of magnitude, location and focal mechanism.

\subsection{The Earthquakes in the South China Sea}

On 9 Oct. 2006, two strong earthquakes with practically identical magnitudes $\left(\mathrm{M}_{\mathrm{L}}=6.1\right)$ occurred (Fig. 4a) in the South China Sea, where the oceanic slab of the Eurasian plate subducts eastward beneath the Luzon islands along the Manila Trench (Fig. 5) (Lin et al. 1999). The CWB catalogue reports that the two strong earthquakes were 57 minutes apart (Fig. 4b) and located at $\left(119.83^{\circ} \mathrm{E}, 20.70^{\circ} \mathrm{N}, 28.0 \mathrm{~km}\right)$ and $\left(119.93^{\circ} \mathrm{E}, 20.77^{\circ} \mathrm{N}, 8.0 \mathrm{~km}\right)$. Since both earthquakes were $160 \sim 170 \mathrm{~km}$ southwest of Taiwan, the CMT solutions determined by the BATS were not well constrained due to poor station coverage. Instead, the NEIC CMT solutions are used. As shown in Fig 4a. both focal mechanism solutions show pure normal faults striking in the NW-SE direction. In the following few days, the doublets were followed by more than 200 aftershocks, clustered around the hypocenter of the second strong earthquake (Fig. 4a).

\subsection{The Hengchun Earthquakes}

On 26 December 2006, two major earthquakes of all but almost equal magnitude $\left(\mathrm{M}_{\mathrm{L}}=7.0\right)$ occurred offshore of Hengchun at the southern tip of Taiwan (Fig. 6a). The hypocenters of the doublet-shocks were located at $\left(120.56^{\circ} \mathrm{E}\right.$, $\left.21.68^{\circ} \mathrm{N}, 41.1 \mathrm{~km}\right)$ and $\left(120.42^{\circ} \mathrm{E}, 21.97^{\circ} \mathrm{N}, 44.0 \mathrm{~km}\right)$ and with a mere 8 -minute time delay between them (Fig. 6b). Most of the aftershocks were clustered around the location of the $2^{\text {nd }}$ major earthquake (Fig. 6a). These earthquakes are interpreted to be a part of the east-dipping Wadati-Benioff zone (Fig. 5). The BATS focal mechanisms show the $1^{\text {st }}$ earthquake to be a pure normal faulting, and the $2^{\text {nd }}$ one as a strike-slip focal mechanism with a normal faulting component. Based on conventional concepts, the $2^{\text {nd }}$ earthquake was more like the mainshock not only because its magnitude was larger, albeit only slightly, than the $1^{\text {st }}$ one but also because most of the aftershocks were clustered around it. In fact, it was previously reported that the $1^{\text {st }}$ earthquake could be considered the foreshock because it was by and large absent of aftershocks (Lin 2004).

In addition to general seismic features mentioned above, it might be interesting to see the b-values from three earth- (a)

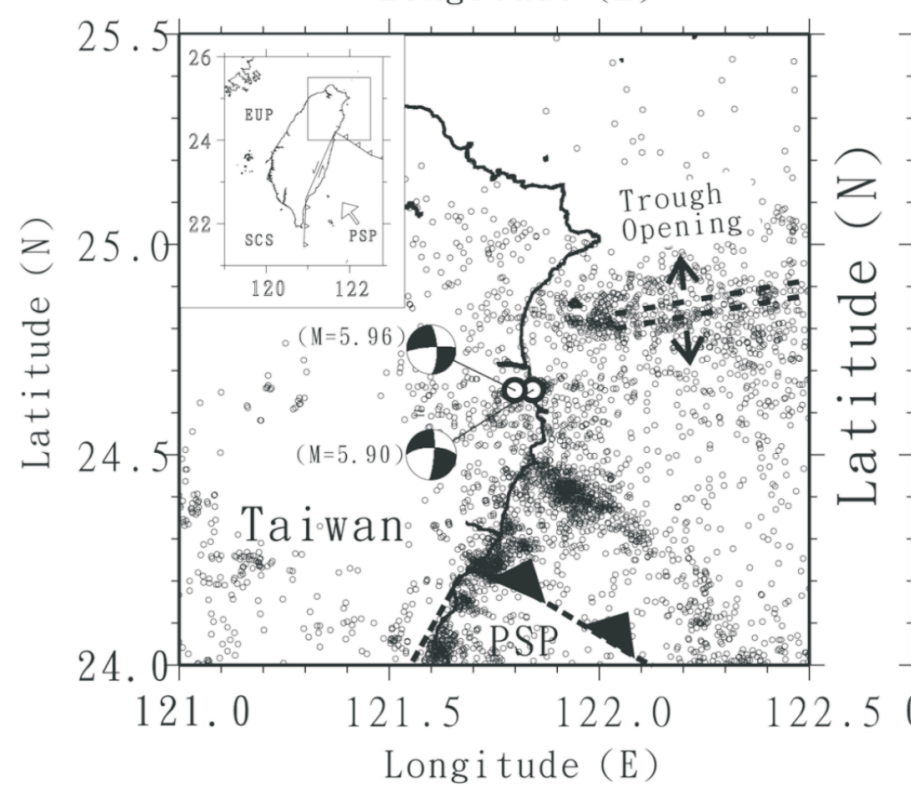

(b)

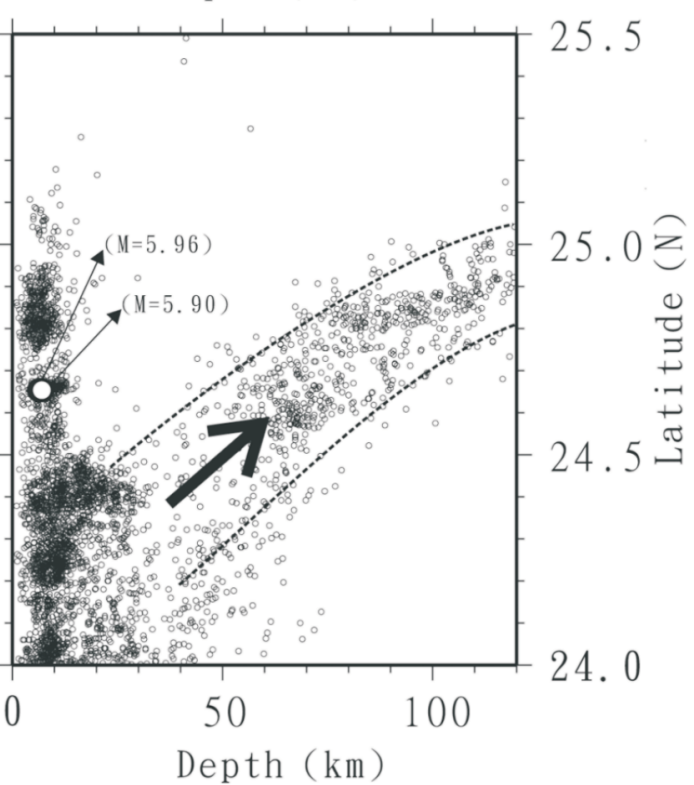

Fig. 3. (a) Locations of background seismicity (small circles) and earthquake doublets (large circles) with focal mechanisms in the northern Taiwan area, and (b) projections of all earthquakes along the N-S profile for showing the northward subduction (a large arrow). 

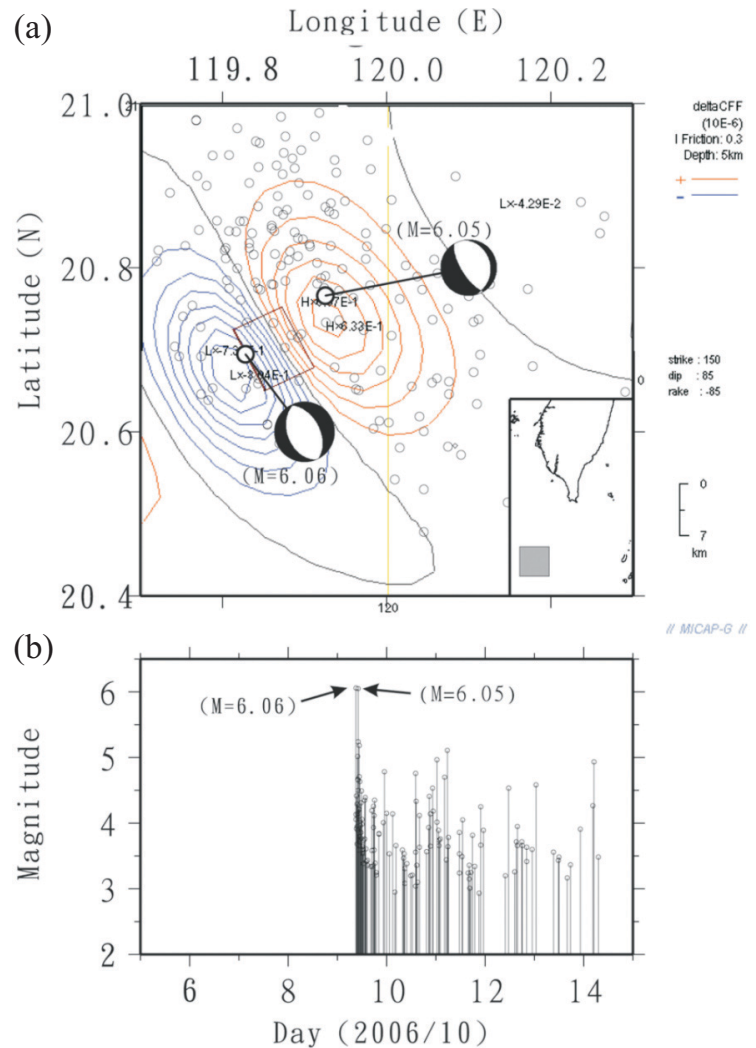

Fig. 4. (a) Seismicity and focal mechanisms of the two strong earthquakes in the South China Sea earthquake sequence. The delta CFF is calculated at the depth of $5 \mathrm{~km}$. (b) Time variations in the earthquake sequence.
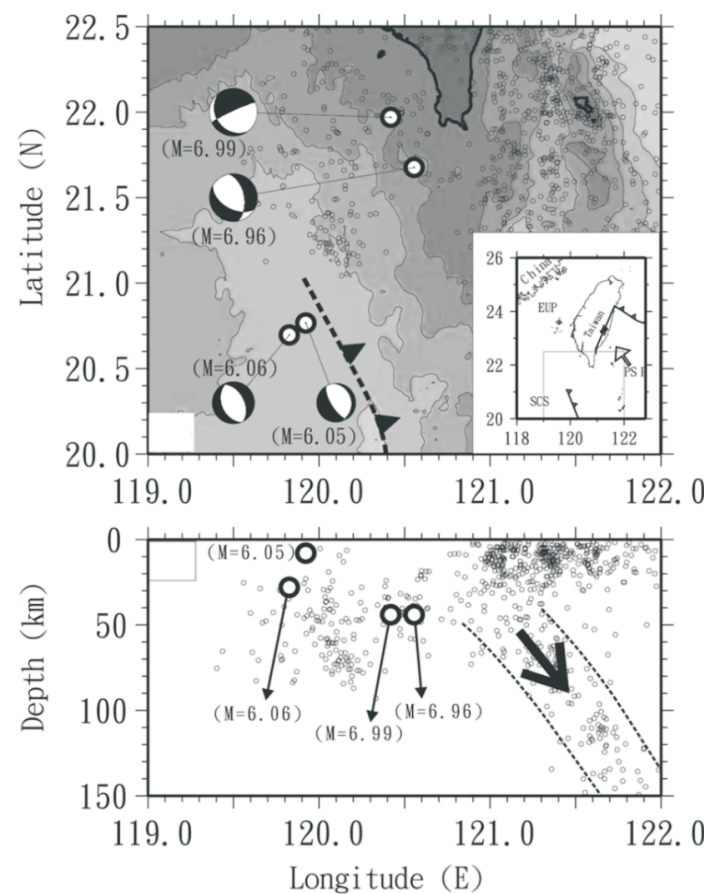

Fig. 5. (a) Locations of background seismicity (small circles) and two earthquake doublets (large circles) with focal mechanisms and (b) projections of earthquakes along the W-E profile for showing eastward subduction (a large arrow). quake sequences with the doublets. Figure 7 shows that the aftershocks of the three doublet-shocks earthquake sequences are very similar, around 0.75 or 0.76 . Those b-values are smaller than the average value of $b=1.1$ obtained from shallow earthquakes in Taiwan (Wang 1988). The results indicate that the aftershocks are skewed toward larger magnitudes for those three sequences when compared to that of background seismicity in general.

\section{DISCUSSION}

The doublets discussed in this paper have similar magnitudes (less than 0.1 ), relatively short delays between the two events in each pair ( 2 to 57 minutes) and occurred within a short distance of each other (several to tens of kilometers). Furthermore, it is worth noting that the largest two earthquakes in both of the Suao and South China Sea earthquake sequences had almost the same focal mechanisms.

To explore how a doublet may occur we consider two possible hypotheses. First, the strain could have been released and then accumulated soon or immediately after the $1^{\text {st }}$ earthquake occurred. However, since the recurrence in-

(a) Longitude (E)
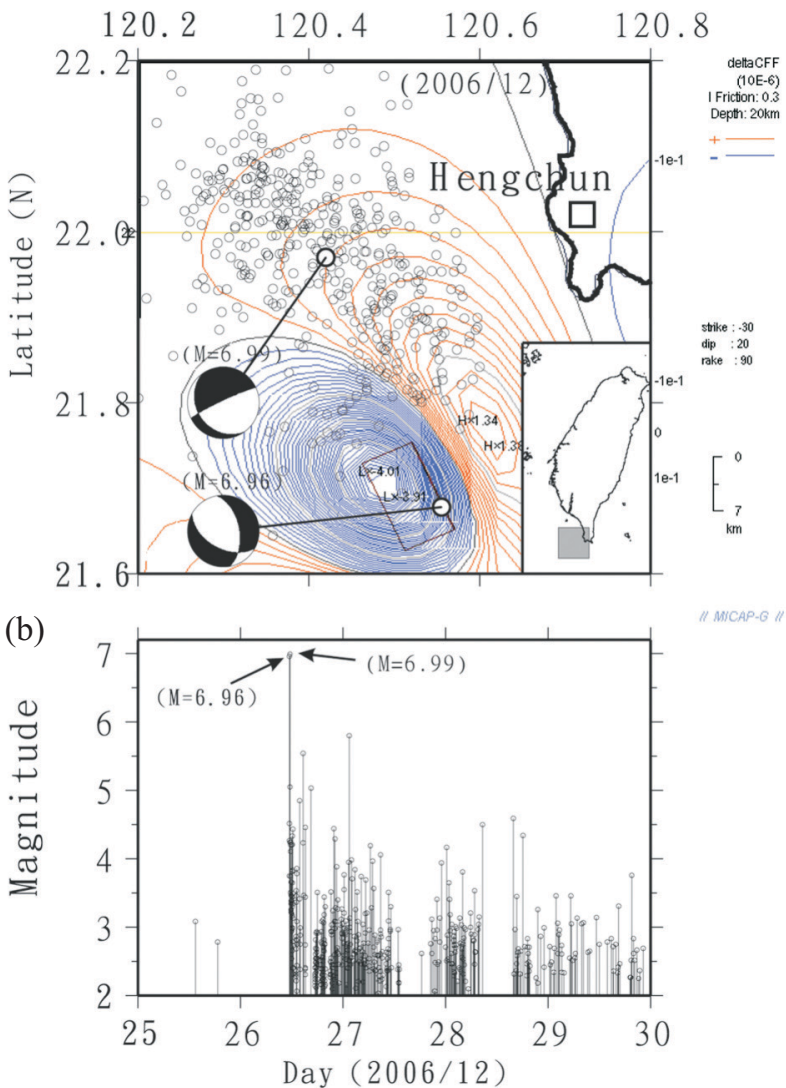

Fig. 6. (a) Seismicity and focal mechanisms of the two strong earthquakes in the Hengchun earthquake sequence. The delta CFF is calculated at the depth of $20 \mathrm{~km}$. (b) Time variations in the earthquake sequence. 

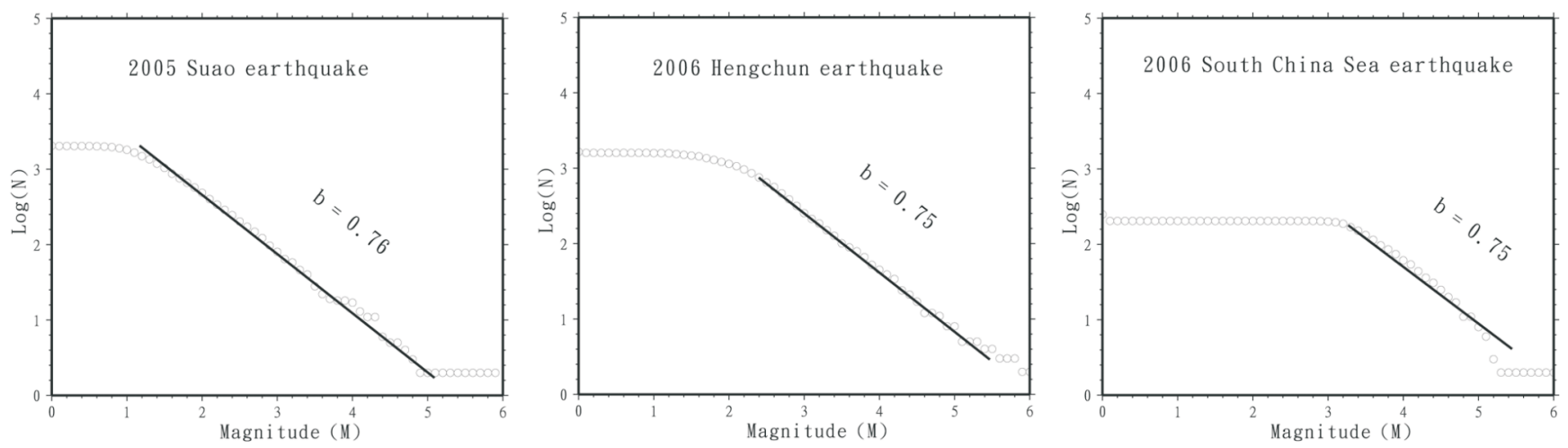

Fig. 7. Plots of accumulative number of earthquakes versus magnitude from three earthquake sequences (2005 Suao, 2006 Hengchun, and 2006 South China Sea).

terval of an $\mathrm{M}_{\mathrm{L}}=5.9 \sim 7.0$ earthquake is normally on the order of years, or tens of years, not in several or tens of minutes, this is not a tenable idea. The second possibility is that the seismic energy of the $2^{\text {nd }}$ earthquake had been stored within an isolated volume at the vicinity of the $1^{\text {st }}$ one. Such a model could work for three doublets as they are located in fairly complex tectonic zones (Fig. 1), where crustal asperities may be abundant. For example, the Suao doublet took place at the complex conjunction between the subducting Philippine Sea plate and the opening Okinawa Trough (Fig. 3). The other two doublets occurred around the tectonic transition zone from the Luzon subduction to Taiwan collision (Fig. 5). In other words, the accumulated seismic energy for the doublet-shocks in each sequence might very well have been separated by strong aspereities in the crust. However, it is not clear why doublets should have nearly identical magnitude.

To further understand the possible relationship between the two events in the Suao, South China Sea, and Hengchun doublets, we calculate the the delta CFF (temporal changes in Coulomb Failure Function) generated by the $1^{\text {st }}$ largest earthquake using the elastic dislocation of a rectangular fault in a half-space (Okada 1985, 1992). Based on the CMT solutions of the $1^{\text {st }}$ largest earthquake, we assume three inclined dip-slip faults (Table 1) to estimate the change in the delta CFF from the dislocation theory of an earthquake source. We use the strike, dip, and rake of the fault as well as the fault depth have been obtained directly from the CMT solutions. The fault depth in the calculated dislocation model is measured from the top of a fault. But the fault length, width and slip have been roughly estimated from the earthquake magnitude since they cannot be exactly obtained without further observations and analyses. Although the calculated delta CFF is also affected by the selection of these fault parameters, the general pattern of the delta CFF is not very sensitive to them. In other words, variations in fault length, width and slip do change the contour lines of the delta CFF, but the areas where the delta CFF increased mostly remain the same.

The calculated results clearly show that the $2^{\text {nd }}$ largest earthquake as well as most of the aftershocks clustered in areas where the delta CFF increased after the $1^{\text {st }}$ largest earthquake (Figs. 2, 4, and 6). Such a good consistency between the increased delta CFF patterns and the subsequent earthquakes, including the $2^{\text {nd }}$ largest earthquake and most aftershocks, indicates that the earthquakes that followed were likely triggered by the static stress generated by the $1^{\text {st }}$ largest earthquake. This result is similar to previous findings with respect to static stress triggering (e.g., King et al. 1994; Stein et al. 1994; Deng and Sykes 1997; Gomberg et al. 1998; Stein 1999; Ammon et al. 2008), rather than from dynamic triggering (Freed 2005). Alternatively, the triggering of $2^{\text {nd }}$ largest earthquake might be a result of rupture propagation beyond fault discontinuities (Kase and Kuge 2001; Duan and Oglesby 2006; Kase and Day 2006). However, the detailed relationship between the events in a doublet should be investigated further.

In addition we would like to point out the potential hazard the $2^{\text {nd }}$ earthquake could cause, perhaps even more

Table 1. Fault parameters of the three earthquake sequences in the Suao, South China Sea, and Hengchun areas.

\begin{tabular}{clccrrrr}
\hline Fault & Strike & Dip & Rake & Slip & Depth & Width & Region \\
\hline $\mathrm{A}$ & $\mathrm{N} 85^{\circ} \mathrm{E}$ & $65^{\circ} \mathrm{N}$ & $-10^{\circ}$ & $10 \mathrm{~cm}$ & $5 \mathrm{~km}$ & $5 \mathrm{~km}$ & Suao \\
$\mathrm{B}$ & $\mathrm{N} 30^{\circ} \mathrm{W}$ & $50^{\circ} \mathrm{W}$ & $128^{\circ}$ & $200 \mathrm{~cm}$ & $35 \mathrm{~km}$ & $10 \mathrm{~km}$ & Hengchun \\
$\mathrm{C}$ & $\mathrm{N} 25^{\circ} \mathrm{W}$ & $48^{\circ} \mathrm{E}$ & $85^{\circ}$ & $30 \mathrm{~cm}$ & $20 \mathrm{~km}$ & $10 \mathrm{~km}$ & $\mathrm{~S}$ China Sea \\
\hline
\end{tabular}


than the $1^{\text {st }}$ one, not only because the magnitude of the $2^{\text {nd }}$ earthquake is at least or nearly that of the $1^{\text {st }}$ one but also because structures damaged during the first one are likely to be destroyed by the second one. The Hengchun earthquake sequence is a prime example of this. A house in the town of Hengchun was partially damaged by the first earthquake, but nobody was killed but the seond one totally destroyed the house. Therefore, in the case of earthquake doublets rescue work in buildings where the construction is made unsound because of the $1^{\text {st }}$ earthquake becomes ever so much more dangerous if the seismic energy of the $2^{\text {nd }}$ earthquake is same as that of the $1^{\text {st }}$.

\section{CONCLUSION}

Three earthquake sequences with two identical largest earthquakes have been observed in Taiwan recently. The two largest earthquakes in each earthquake sequence formed doublets, having similar magnitude and focal mechanisms, close to each other, and with a relatively short delay between them. These doublets differ from the more common mainshock and aftershock sequences. We found that the second shock in the doublets and most of the aftershocks were located generally in the region of increased static stress following the first shock, suggesting that these events were triggered by the first through static stress transfer. We propose that for doublets similar to those we studied the seismic energy of the doublets have been independently accumulated within adjacent volumes separated by an asperity. In other words, the triggered earthquake could be as large as the $1^{\text {st }}$ largest earthquake and thus the rescue work becomes more dangerous in the strongly crustal heterogeneous area.

Acknowledgements The authors would like to thank the Central Weather Bureau in Taipei for providing the Earthquake Catalogue in Taiwan. Gratitude is also extended to our colleagues (such as W. T. Liang) at the Institute of Earth Sciences, Academia Sinica who carefully inverted the CMT solutions using the broadband seismic data (BATS). This study was partially supported by the National Science Council of Taiwan. The static stress change is estimated by using the MICAP-G software. The comments and suggestions by W. H. Wang, F. T. Wu, and another anonymous reviewer really help to improve the paper.

\section{REFERENCES}

Ammon, C. J., H. Kanamori, and T. Lay, 2008: A great earthquake doublet and seismic stress transfer cycle in the cen- tral Kuril islands. Nature, 451, doi: 10.1038/nature06521.

Deng, J. and L. R. Sykes, 1997: Evolution of the stress field in southern California and the triggering of moderate-size earthquakes: A 200-year perspective. J. Geophys. Res., 102, 9859-9886.

Duan, B. and D. D. Oglesby, 2006: Heterogeneous fault stresses from previous earthquakes and the effect on dynamic of parallel strike-slip faults. J. Geophys. Res., 111, B05309, doi: 10.1029/2005BJ004138.

Freed, A. M., 2005: Earthquake triggering by static, dynamic and postseismic stress transfer. Annu. Rev. Earth Planet. Sci., 22, 335-367.

Gomberg, J., N. M. Beeler, M. L. Blanpied, and P. Bodin, 1998: Earthquake triggering by transient and static deformations. J. Geophys. Res., 103, 24411-24416.

Kao, H. and P. R. Jian, 1999: Source parameters of regional earthquakes in Taiwan: July 1995 - December 1996. Terr. Atm. Ocean., 10, 585-604.

Kase, Y. and K. Kuge, 2001: Rupture propagation beyond fault discontinuities: Significance of fault strike and location. Geophys. J. Int., 147, 330-342.

Kase, Y. and S. M. Day, 2006: Spontaneous rupture processes on a bending fault. Geophys. Res. Lett., 33, L10302.

King, G. C. P., R. S. Stein, and J. Lin, 1994: Static stress changes and the triggering of earthquakes. Bull. Seismol. Soc. Am., 84, 935-955.

Lin, C. H., 2004: Repeated foreshock sequences in the thrustfaulting environment of eastern Taiwan. Geophys. Res. Lett., 31, L13601.

Lin, C. H., B. S. Huang, and R. J. Rau, 1999: Seismological evidence of a low-velocity layer within the subducted slab of southern Taiwan. Earth Planet. Sci. Lett., 174, 231-240.

Liu, C. C., 1995: The Ilan Plain and the southwestward extending Okinawa Trough. J. Geol. Soc. China, 38, 183-193.

Okada, Y., 1985: Surface deformation due to shear and tensile faults in a half-space. Bull. Seismol. Soc. Am., 75, 1135-1154.

Okada, Y., 1992: Internal deformation due to shear and tensile faults in a half-space. Bull. Seismol. Soc. Am., 82, 10181040.

Shin, T. C., K. W. Kuo, W. H. K. Lee, T. L. Teng, and Y. B. Tsai, 2000: A preliminary report on the 1999 Chi-Chi earthquake. Seismol. Res. Lett., 71, 23-29.

Stein, R. S., 1999: The role of stress transfer in earthquake occurrence. Nature, 402, 605-609.

Stein, R. S., G. C. King, and J. Lin, 1994: Change in failure stress on the southern San Andreas fault system caused by the 1992 magnitude $=7.4$ Landers earthquake. Science, 258, 1328-1332.

Wang, J. H., 1988: b values of shallow earthquakes in Taiwan. Bull. Seismol. Soc. Am., 78, 1243-1254. 